\title{
The Effect of Comfrey on Enoxaparin-Induced Bruise in Patients with Acute Coronary Syndrome: A Randomised Clinical Trial
}

\author{
Zahra Bagheri ${ }^{1}$, Azim Azizi ${ }^{2}$, Khodayar Oshvandi ${ }^{1}$, Younes Mohammadi ${ }^{3}$, Amir Larki-Harchegani ${ }^{4,5}{ }^{4}$ \\ ${ }^{1}$ Department of Medical Surgical Nursing, School of Nursing and Midwifery, Hamadan University of Medical Sciences, Hamadan, Iran \\ ${ }^{2}$ Chronic Diseases (Home Care) Research Center, Malayer School of Nursing, Hamadan University of Medical Sciences, Hamadan, Iran \\ ${ }^{3}$ Department of Epidemiology, School of Public Health, Hamadan University of Medical Sciences, Hamadan, Iran \\ ${ }^{4}$ Department of Pharmacology and Toxicology, School of Pharmacy, Hamadan University of Medical Sciences, Hamadan, Iran \\ ${ }^{5}$ Medicinal Plants and Natural Products Research Center, Hamadan University of Medical Sciences, Hamadan, Iran
}

Received July 29, 2021

Reviewed October 24, 2021

Accepted November 26, 2021

*Corresponding Author Amir Larki-Harchegani Department of Pharmacology and Toxicology, School of Pharmacy, Hamadan University of Medical Sciences, Hamadan, Iran Tel: +98-81-3838-1591 E-mail: dr.amir.larki@gmail.com
Objectives: Bruising is an important side effect of enoxaparin injection. Comfrey (Symphytum officinale) is used to treat different types of wounds, bone fractures, and bruising in traditional medicine in many countries for centuries. This study aimed to determine the effects of the Comfrey ointment on the bruise size and color following enoxaparin injection. Methods: This double-blind randomized clinical trial was conducted on 80 patients with acute coronary syndrome (ACS). The participants were randomly divided into two groups of 40 , namely Comfrey and Placebo. Changes in bruise size and color in both groups were assessed daily before and after the intervention.

Results: The Comfrey and Placebo groups were homogeneous in demographic and clinical variables. A downward trend was observed in the bruise size in both groups throughout the study. However, the bruise size was smaller in the Comfrey group than the Placebo group on day 2-5 of the intervention. Moreover, there was a significant difference in bruise color between the groups, with a shorter healing course in the Comfrey group.

Conclusion: The Comfrey ointment accelerated the healing process of enoxaparin injection-induced bruising in patients with ACS. It is recommended as a safe and simple approach for these patients.

Keywords: bruise, enoxaparin, comfrey, acute coronary syndrome, patient, ointment

\section{INTRODUCTION}

Acute Coronary Syndrome (ACS) is a general term for the signs and symptoms of myocardial ischemia [1]. Patients with ACS take many drugs, specifically enoxaparin, to control symptoms and complications [2]. Enoxaparin is a low molecular weight anticoagulant administered as a subcutaneous injection [3].

Despite many advantages, enoxaparin has side effects such as pain, anemia, hematoma, thrombocytopenia, and injection site bruising $[4,5]$. Bruising is defined as skin color change in a surface area of equal or larger than $2 \mathrm{~mm}^{2}$ [6]. This side effect is the result of bleeding from damaged vessels into the subcutane- ous tissue. The bruise maximizes over 48 hours and then slowly starts resolving after 60 to 72 hours. However, complete healing typically occurs between two to three weeks $[7,8]$.

One of the most important responsibilities of a nurse towards patients is to prevent injury and discomfort and maintain safety [9]. Nevertheless, despite following standard patient care protocols, there are different degrees of discomfort and bruising with injections [10]. Enoxaparin injection-induced bruising occurs in $53.6 \%$ of patients with ACS [11]. A bruise can also disrupt physical and psychological comfort, impair mental selfimage, and reduce self-confidence [12].

Nurses must reduce the fear and concern of patients regarding nursing interventions and care delivery. As a result, nurses 
should look for new methods to reduce such issues through professional development and research [13]. A literature review showed that different methods can be used to reduce the bruise size at the injection site, such as using cold and warm compresses [10], changing the needle length and diameter [14], cooling the injection site [15], and changing the injection angle [16] and speed [13]. Almost all of these methods can prevent bruising. According to databases such as Google Scholar and PubMed, there are no studies examining bruise size reduction and bruise healing in patients with ACS.

Comfrey (Symphytum officinale) is a medicinal plant used in traditional medicine to cure bruises. As a member of the Boraginaceae family, Comfrey is native to Europe and tropical regions in Asia. It has anti-inflammatory and pain-relieving effects, stimulates granulation, accelerates fractures, tissue regeneration, wound healing, and bruise, and improves rheumatic disorders, muscular pain, and sport-induced sprain [17-23]. The beneficial effects of this plant on cellular metabolism and cell survival of human skin fibroblasts have been proven [21]. Researchers attributed the medicinal effects of Comfrey to three major compounds, namely phenolic acids (rosmarinic acid, caffeic acid, and salicylic acid), amine (allantoin), glycopeptides, and mucilage polysaccharides [24]. Allantoins stimulate cellular metabolism and growth in subcutaneous tissue as well as bone, tendon, and ligament. On the other hand, rosmarinic acid has antioxidant and anti-inflammatory effects and inhibits the syn- thesis of prostaglandins [25].

Given the inevitable side effects of drugs such as enoxaparin injection-induced bruises in some patients $[10,13]$, the antibruise and anti-inflammatory effects of Comfrey in traditional medicine [26], and the lack of a comprehensive scientific study into the effect of Comfrey on bruises, this study aimed to determine the effect of Comfrey on the size and color of enoxaparin injection-induced bruises in patients with ACS.

\section{MATERIALS AND METHODS}

\section{Study design}

This randomized clinical trial was conducted on two homogeneous groups in the CCU and Heart Department of Farshchian Heart Hospital of Hamadan from July 2020 to July 2021.

97 participants enrolled in the study. 13 patients were excluded from the study due to non-compliance with the inclusion criteria, and the remaining 84 participants were randomly assigned to the Comfrey or Placebo groups, in a parallel-group scheme (1:1 ratio) using a permuted block randomization with a block size of four. Two participants in each group refused to continue with the study. 40 patients in each group were present until the end of the study (Fig. 1).

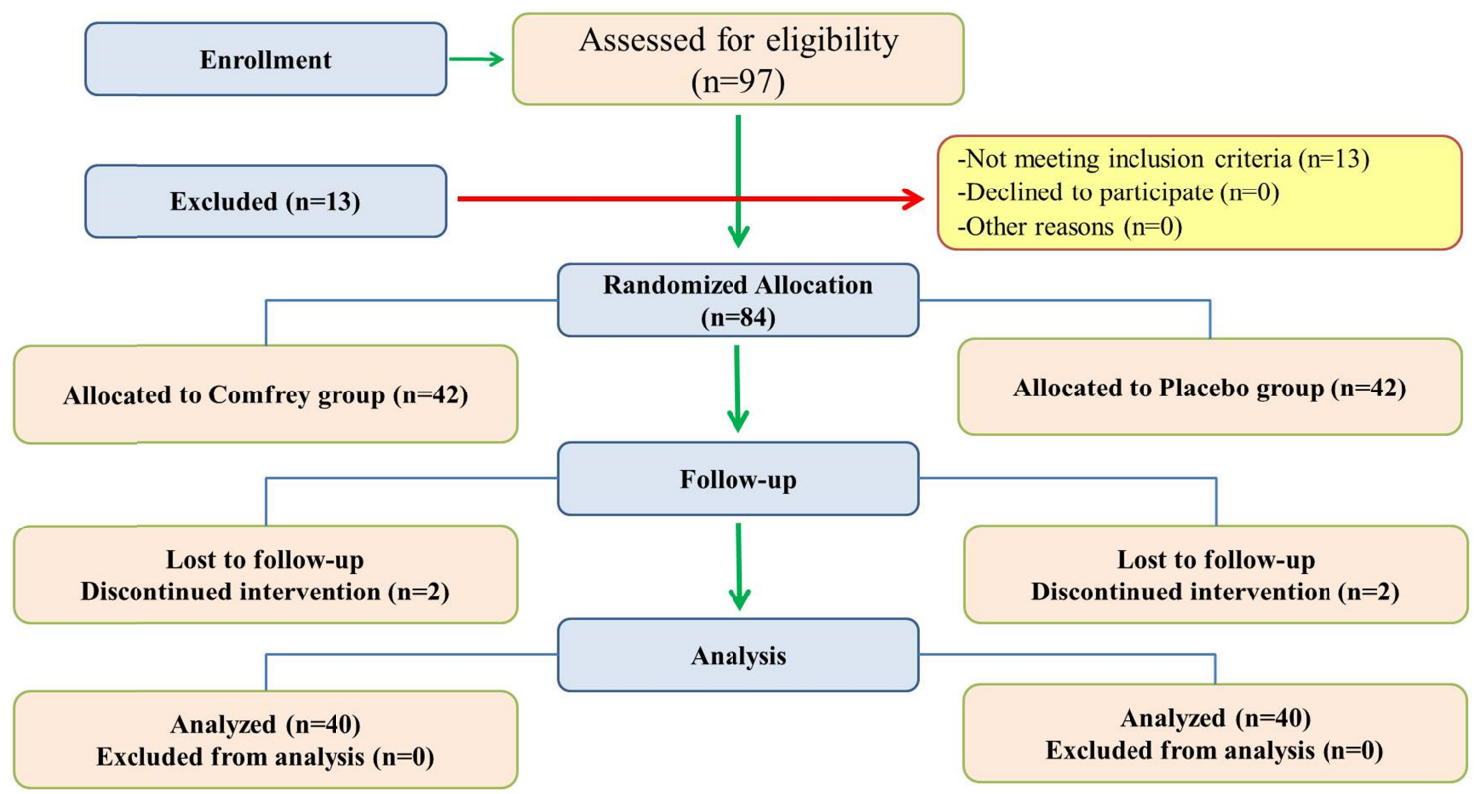

Figure 1. Flow diagram of the patients in the Comfrey and Placebo groups throughout the different phases of the trial. 


\section{Participants and study setting}

The research sample included eligible patients with ACS who received enoxaparin $(1 \mathrm{mg} / \mathrm{kg}$ with a maximum dose of $90 \mathrm{mg}$ twice a day). The inclusion criteria were bruising (at least $1 \mathrm{~cm}^{2}$ ) caused by enoxaparin injection, age group of 30-85 years, no food and drug allergy, no coagulation problem, consciousness, not taking warfarin, heparin, and anti-inflammatory drugs (Glucocorticosteroids and NSAIDs), the injection site on the abdomen, and bruising less than 12 hours old. The exclusion criteria were allergy to employed ointments, early discharge, the occurrence of acute coagulation disorders, repeated injection into the bruising area, enoxaparin withdrawal, and not taking the drug twice a day.

\section{Ethics statements}

All procedures in this study were done in agreement with the ethical standards of the institutional research committee and with the 1964 Helsinki declaration. The research was approved by the Ethics Committee of Hamadan University of Medical Sciences (IR.UMSHA.REC.1397.471). The study objectives were explained to the patients and all patients signed a written informed consent form to declare their agreement to participate in this study. This trial was registered in the Iranian Registry of Clinical Trials (http://www.irct.ir; IRCT2015062822956N1).

\section{Sample size}

Following a previously published trial (Jeffrey et al., 2015), the equation for calculating the sample size in randomized clinical trials was used in the present study, where type one error $(\alpha)$ was 0.05 , type two errors $(\beta)$ was 0.10 (power $=0.90$ ), the difference in mean (d) of bruise size was $10 \mathrm{~mm}$, and the standard deviation (SD) was 10.

$$
n=\left(Z_{1-\frac{a}{2}}+Z_{1-\beta}\right)^{2} / d \quad \text { where: } d=\left(D_{1}-D_{2}\right) /(\sigma \sqrt{2})
$$

Assuming the probable loss to follow-up of $20 \%$ in each group, a total of 40 participants was considered as the final sample size for each group [27].

\section{Randomization and blinding}

The eligible participants were assigned to the Comfrey and placebo groups using permuted block randomization technique with a block size of four and an equal allocation ratio. Microsoft Excel 2016 software (Microsoft Corp., Redmond, WA, USA) was used to create random sequences of block sizes. To blind the study, the Comfrey and placebo groups were denoted by letters A and B, respectively. The researcher, patients, and statisticians were blinded to the groups until the end of the data analysis stage.

\section{Plant materials}

The plant (Symphytum officinale) was purchased from the Avicenna Herb Garden in Hamadan in early summer 2018 and then approved by a botanical specialist in Hamadan University of Medical Sciences. The herbal specimen was deposited in the herbarium (voucher number PMP-1329).

\section{Preparation of Comfrey hydro-alcoholic extract}

A total of $200 \mathrm{~g}$ of the dried plant was first ground and then suspended in ethanol $70 \%$ and subjected to continuous ultrasonic vibrations (USV) for three days. The suspension was stirred gently several times during this period. The obtained extract was then filtered using the Whatman ${ }^{\circledR}$ filter paper No. 30 and condensed using a rotary evaporator. The solution was then placed in a $30-40^{\circ} \mathrm{C}$ oven to obtain the dry extract [28]. After weighing, the percent of extraction from the plant sample was calculated as $18.5 \%(\mathrm{w} / \mathrm{w})$.

\section{Preparation of Comfrey ointment}

The dried smoothed powder of Comfrey hydro-alcoholic extract was mixed with eucerin as the base of ointment to prepare the Comfrey ointment $10 \%(\mathrm{w} / \mathrm{w})$. A homogenizer was used to achieve a uniform ointment with acceptable appearance characteristics [29].

\section{Preparation of placebo ointment}

The placebo ointment was also eucerin-based, to which appropriate neutral food dye was added to achieve the same color as the Comfrey ointment and then placed in similar tubes.

The Comfrey and placebo ointments were prepared by a pharmacist in the laboratory of biopharmaceutical products, school of pharmacy, Hamadan University of Medical Sciences, 
Hamadan, Iran.

\section{Data collection instruments}

Demographic and clinical information of all participants was recorded and assessed by designing a questionnaire. Moreover, the bruise size and color in both groups were determined before the intervention and the days 1 to 5 of the intervention. To reduce the error rate in reporting the results, all bruise size and color measurements were taken at a fixed time ( $9 \mathrm{am}$ ) during the research period. The bruise size was recorded by placing a transparent paper strip on the bruise and coloring the spot with a fine-tip permanent marker. The measurement was replicated three times. Then, the paper was scanned by a scanner and the accurate bruise size was obtained in $\mathrm{mm}^{2}$ in ImageJ software version $1.52 \mathrm{n}$. The bruise color was determined using a bruising color chart, reflecting four key bruise color changes from the onset to healing, and the dominant color was recorded. To investigate the reliability of the observers, the size and color of the bruise complication in ten patients were measured separately by the main researcher (the assessor) and three trained nurses at the same time, and the intraclass correlation coefficient (ICC) of 0.93 and 0.90 were obtained, respectively, indicating very good reliability [17]. After the initial evaluation of the bruise size and color, the participants in Group A received Comfrey ointment on the enoxaparin injection-induced bruising site. The ointment was administered four times per day with 6-hour intervals for five consecutive days. The participants in Group $B$ underwent the same procedure, except that they received the Placebo ointment instead of Comfrey ointment. The amount of ointment used varied from patient to patient, depending on the size of the bruised area. Approximately $0.3 \mathrm{~g}$ of ointment was

Table 1. Distribution of participants' qualitative demographic characteristics between the two study groups

\begin{tabular}{|c|c|c|c|c|c|c|}
\hline \multirow[t]{2}{*}{ Variables } & \multirow[t]{2}{*}{ Sub groups } & \multicolumn{2}{|c|}{$\begin{array}{l}\text { Comfrey group } \\
\qquad N=40\end{array}$} & \multicolumn{2}{|c|}{$\begin{array}{l}\text { Placebo group } \\
\qquad N=40\end{array}$} & \multirow[t]{2}{*}{$p$ value } \\
\hline & & Number & Percent & Number & Percent & \\
\hline \multirow[t]{2}{*}{ Gender } & Female & 16 & 40 & 19 & 47.5 & 0.435 \\
\hline & Male & 24 & 60 & 21 & 52.5 & \\
\hline \multirow[t]{3}{*}{ Marital status } & Married & 34 & 85 & 38 & 95 & 0.311 \\
\hline & Single & 2 & 5 & 0 & 0 & \\
\hline & Widow & 4 & 10 & 2 & 5 & \\
\hline \multirow[t]{5}{*}{ Employment status } & Employee & 4 & 10 & 7 & 17.5 & 0.054 \\
\hline & Housewife & 10 & 25 & 16 & 40 & \\
\hline & Retired & 10 & 25 & 7 & 17.5 & \\
\hline & Unemployed & 0 & 0 & 3 & 7.5 & \\
\hline & Freelance job & 16 & 40 & 7 & 17.5 & \\
\hline \multirow[t]{4}{*}{ Education level } & Illiterate & 20 & 50 & 15 & 37.5 & 0.611 \\
\hline & Middle school & 6 & 15 & 10 & 15 & \\
\hline & Diploma & 9 & 22.5 & 9 & 22.5 & \\
\hline & University education & 5 & 12.5 & 6 & 15 & \\
\hline \multirow[t]{3}{*}{ Monthly income } & Under 100 USD & 20 & 50 & 14 & 35 & 0.09 \\
\hline & $100-500$ USD & 16 & 40 & 16 & 40 & \\
\hline & More than 500 USD & 4 & 10 & 10 & 25 & \\
\hline \multirow[t]{2}{*}{ Living place } & City & 26 & 65 & 28 & 70 & 0.633 \\
\hline & Village & 14 & 35 & 12 & 30 & \\
\hline \multirow[t]{2}{*}{ Health insurance } & Insured & 38 & 95 & 36 & 90 & 0.675 \\
\hline & Non-insured & 2 & 5 & 4 & 10 & \\
\hline \multirow[t]{2}{*}{ Smoking status } & Smoker & 23 & 57.5 & 16 & 40 & 0.174 \\
\hline & Non-smoker & 17 & 42.5 & 24 & 60 & \\
\hline
\end{tabular}


applied per $\mathrm{cm}^{2}$ of the bruised area to create a proper coverage of the ointment.

\section{Statistical analysis}

Data were analyzed with ANOVA. Then, Tukey's post hoc test, and paired/unpaired $t$-test and their nonparametric equations were used if needed. The nonparametric assessment of the bruise color of each patient at different times was done using the Mann-Whitney $U$ test. The statistical analysis was done in SPSS20 at the significance level of $p<0.05$. Data were presented in the form of means \pm SEM for all 40 patients in each group.

\section{RESULTS}

There was no significant difference between the groups in demographic information (sex, marital status, job, education, monthly income, place of residence, health-care insurance, smoking, age, BMI, INR, PT, PTT, and serum platelet counts (Tables 1-3).

Fig. 2 shows no significant difference between the groups in the mean bruise size before the intervention $(p=0.494)$. On the first day after the intervention, the mean bruise size in the Comfrey group was lower than in the Placebo group. However, based on the independent $t$-test, there was no significant difference between the groups in the mean bruise size $(p=0.274)$. A significant difference was observed between the groups in the mean bruise size in the second to fifth days of the intervention (Fig. 2) ( p > 0.05) with lower mean bruise size in the Comfrey group. Friedman's test showed a significant difference between the groups in the mean bruise size at the observation times ( $\mathrm{p}$ $<0.001)$. According to Fig. 2, there is a downward trend in the

Table 2. Distribution of participants' quantitative demographic variables between the two study groups

\begin{tabular}{|c|c|c|c|c|c|c|c|}
\hline \multirow{2}{*}{ Variables } & \multicolumn{3}{|c|}{ Experimental group $(\mathrm{N}=40$ ) } & \multicolumn{3}{|c|}{ Placebo group $(\mathrm{N}=40)$} & \multirow{2}{*}{$\mathrm{p}$ value } \\
\hline & Mean \pm SD & Maximum & Minimum & Mean \pm SD & Maximum & Minimum & \\
\hline Age (years) & $64.13 \pm 8.97$ & 79 & 43 & $63.85 \pm 10.49$ & 80 & 41 & 0.900 \\
\hline Weight (kg) & $72.79 \pm 9.27$ & 91 & 58 & $75.95 \pm 9.09$ & 90 & 53 & 0.131 \\
\hline Height (cm) & $168.93 \pm 9.95$ & 189 & 144 & $168.53 \pm 9.97$ & 188 & 155 & 0.858 \\
\hline BMI $\left(\mathrm{kg} / \mathrm{m}^{2}\right)$ & $25.58 \pm 3.21$ & 32.81 & 17.08 & $26.85 \pm 3.5$ & 35.70 & 20.96 & 0.097 \\
\hline
\end{tabular}

Table 3. Distribution of participants' clinical data between the Comfrey and placebo groups

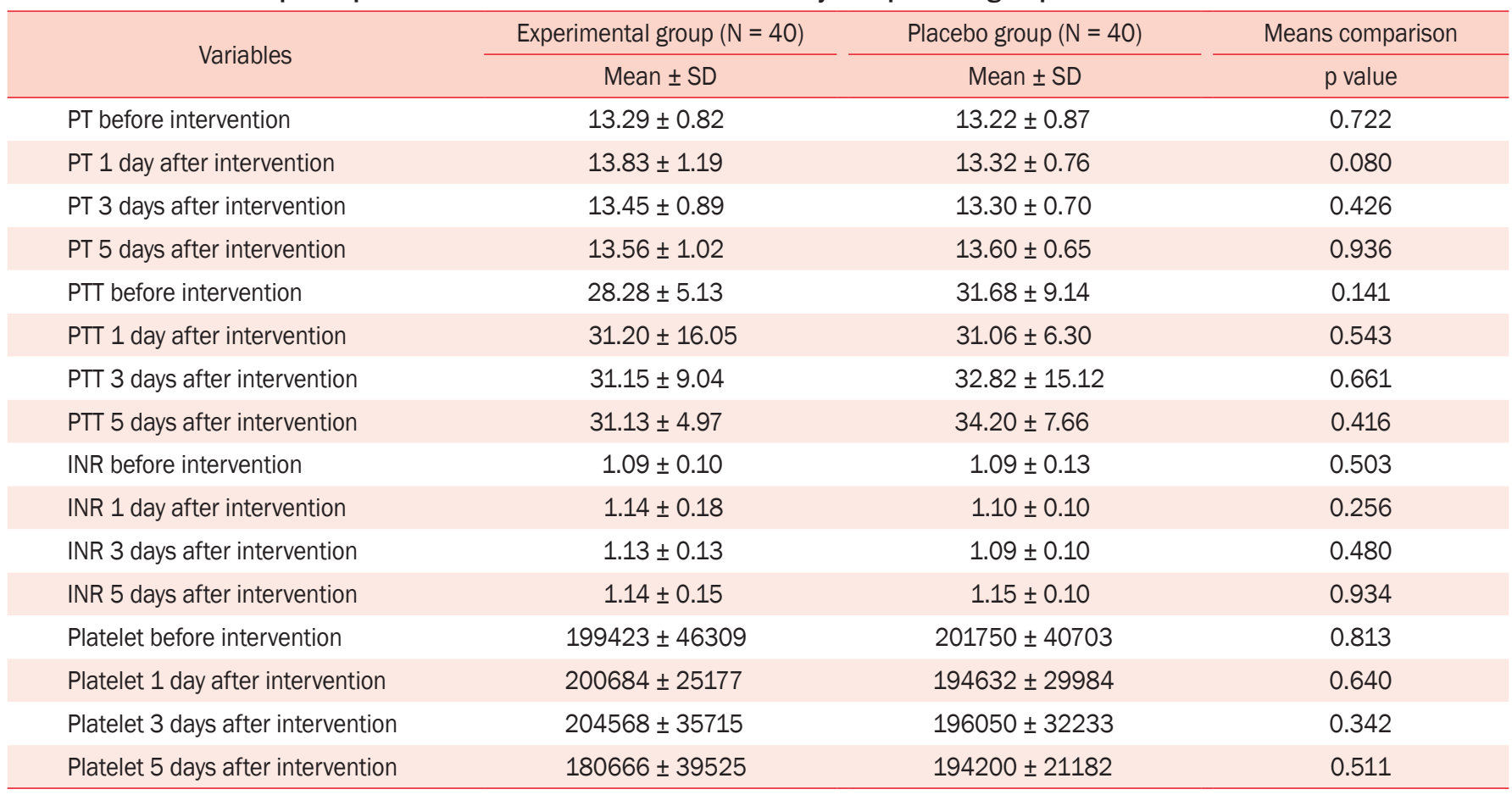


bruise size at the observation point in both groups, specifically in the Comfrey group.

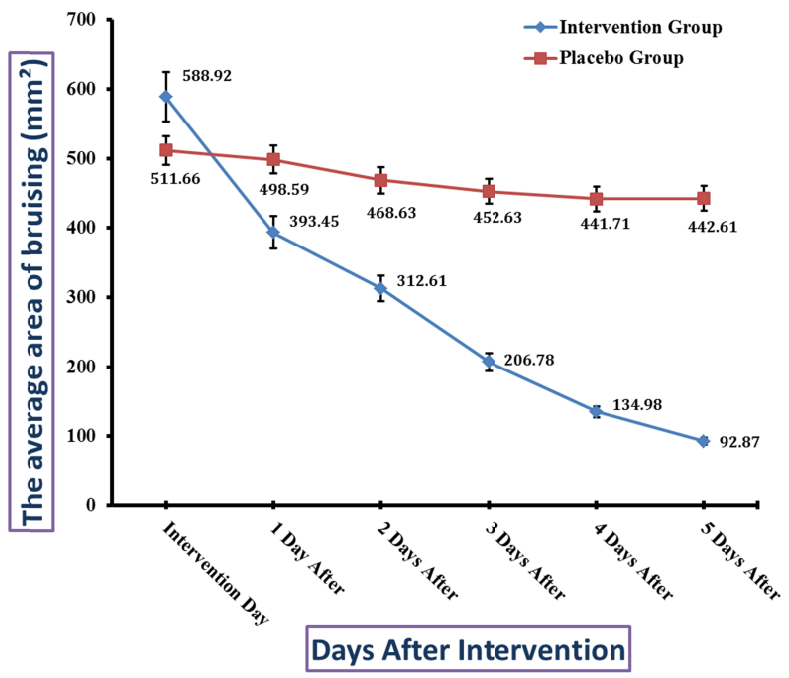

Figure 2. Comparison of bruising size-reduction trend in Comfrey and Placebo groups. There was no significant difference between the Comfrey group and the placebo group in the mean size of bruising before the intervention $(p=0.494)$. Data are presented as mean \pm SEM.
In Table 4 the non-parametric Friedman's test was used to investigate the intervention effect on the bruise size and perform intra-group comparisons before and five days after the intervention. There was a significant difference within both groups in terms of bruise color at all six observation points $(\mathrm{p}<$ 0.001). The bruise color distribution was similar in both groups before the intervention. Comparison of bruise color in the firstto-fifth-day post-intervention showed a significant difference in the bruise color distribution in all five days of the intervention ( $p$ $>0.001)$. In that, the color of the bruised area indicated a faster healing course in the Comfrey group (Fig. 3).

Table 5 shows the probability of bruise color change (KaplanMeier) in both groups after the intervention. According to the results, the probability of change in bruise color was $50 \%$ after the first day of the intervention, which reached $100 \%$ after the second day of intervention in the Comfrey group. This bruise color change was observed in all participants until the second day of intervention in this group. The bruise color change was not observed in any of the placebo control participants one day post-intervention. The probabilities of a change in the bruise color in the second, third, fourth, and fifth days after the inter-

Table 4. Comparison of bruise color before and after intervention between the groups

\begin{tabular}{|c|c|c|c|c|c|c|c|c|c|}
\hline Groups & Bruise color & $\begin{array}{c}\mathrm{T} 1 \\
\mathrm{n}(\%)\end{array}$ & $\begin{array}{c}\text { T2 } \\
\mathrm{n}(\%)\end{array}$ & $\begin{array}{c}\text { T3 } \\
\text { n (\%) }\end{array}$ & $\begin{array}{c}\text { T4 } \\
\mathrm{n}(\%)\end{array}$ & $\begin{array}{c}\text { T5 } \\
\mathrm{n}(\%)\end{array}$ & $\begin{array}{c}\text { T6 } \\
\mathrm{n}(\%)\end{array}$ & $\begin{array}{c}\text { Friedman test } \\
\text { statistic }\end{array}$ & $\mathrm{p}$ value \\
\hline \multirow[t]{4}{*}{ Intervention group } & Pink and red & $40(100)$ & $20(50)$ & 0 & 0 & 0 & 0 & 184.37 & $<0.001$ \\
\hline & Blue and dark purple & 0 & $20(50)$ & 37 (92.5) & $17(42.50)$ & $4(10)$ & 0 & & \\
\hline & Pale green & 0 & 0 & $3(7.5)$ & $22(55)$ & $28(70)$ & 19 (47.5) & & \\
\hline & Yellow and brown & 0 & 0 & 0 & $1(2.5)$ & $8(2)$ & $21(52.5)$ & & \\
\hline \multirow[t]{4}{*}{ Placebo group } & Pink and red & $40(100)$ & $40(100)$ & 34 (85) & $19(47.50)$ & $8(20)$ & $2(5)$ & 140.65 & $<0.001$ \\
\hline & Blue and dark purple & 0 & 0 & $6(15)$ & $21(52.5)$ & $32(80)$ & $34(85)$ & & \\
\hline & Pale green & 0 & 0 & 0 & 0 & 0 & $4(10)$ & & \\
\hline & Yellow and brown & 0 & 0 & 0 & 0 & 0 & 0 & & \\
\hline Statistic & - & $26.57 *$ & $69.91 * *$ & $51.25 * *$ & $76.05 * *$ & $80.78^{*} z^{*}$ & & & \\
\hline$p$ value & - & $<0.001$ & $<0.001$ & $<0.001$ & $<0.001$ & $<0.001$ & & & \\
\hline
\end{tabular}

T1, Before intervention; T2, First day after intervention; T3, Second day after intervention; T4, Third intervention day after intervention; T5, Fourth day after intervention; T6, Fifth day after intervention. *Chi-square test, **Fisher exact test.

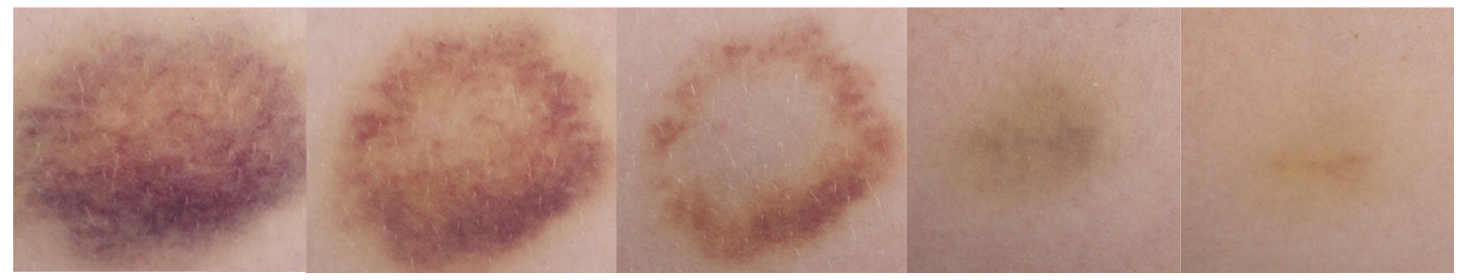

Figure 3. Bruising healing in one patient in the intervention group for the first to fifth days after the intervention (left to right, respectively). 
Zahra Bagheri, et al.

Table 5. Bruise color change probability (Kaplan-Meier estimator) after intervention in the Comfrey and placebo groups

\begin{tabular}{|c|c|c|c|c|c|c|}
\hline Groups & Time of event & Number of events* & Number of risks & $\begin{array}{c}\text { Number of censored } \\
\text { cases }\end{array}$ & $\begin{array}{c}\text { Probability of not } \\
\text { happening }\end{array}$ & $\begin{array}{c}\text { Probability of } \\
\text { happening }\end{array}$ \\
\hline \multirow[t]{4}{*}{ Comfrey group } & $\mathrm{T} 1$ & 0 & 40 & 0 & 1 & 0 \\
\hline & $\mathrm{T} 2$ & 20 & 40 & 0 & 0.50 & 0.50 \\
\hline & T3 & 20 & 20 & 0 & 0 & 1 \\
\hline & $>\mathrm{T} 3$ & - & - & - & - & - \\
\hline \multirow[t]{6}{*}{ Placebo group } & $\mathrm{T} 1$ & 0 & 40 & 0 & 1 & 0 \\
\hline & $\mathrm{T} 2$ & 0 & 40 & 0 & 1 & 0 \\
\hline & T3 & 6 & 40 & 0 & 0.85 & 0.25 \\
\hline & T4 & 15 & 34 & 0 & 0.48 & 0.52 \\
\hline & T5 & 11 & 19 & 0 & 0.20 & 0.80 \\
\hline & T6 & 6 & 8 & 2 & 0.05 & 0.95 \\
\hline
\end{tabular}

T1, Before intervention; T2, First day after intervention; T3, Second day after intervention; T4, Third intervention day after intervention; T5, Fourth day after intervention; T6, Fifth day after intervention. *Bruise color change.

vention were $25 \%, 52 \%, 80 \%$, and $95 \%$, respectively.

\section{DISCUSSION}

There was a significant difference between the groups in the mean bruise size at the assessment times. In addition, a downward trend was observed in the bruise size at different time points in both groups. To establish whether there is a difference between the groups in the bruise size reduction, the Comfrey and Placebo groups were compared at different time points and the results showed that the groups were homogeneous in this regard before the intervention. Although the mean bruise size in the Comfrey group was smaller than the Placebo group on the first day after the intervention, this difference between the groups was not significant. However, the difference between the groups in the mean bruise size was significant at 2-5 days with a smaller mean bruise size in the Comfrey group. As a result, the use of Comfrey ointment can reduce the size of enoxaparin injection-induced bruises. This finding confirmed the research hypothesis that Comfrey ointment affects the size of enoxaparin injection-induced bruises.

Inconsistent with this study, Barna et al. [30] showed no significant difference in wound healing of the control group before and after the intervention. Moreover, Chaiet et al. [31] showed no significant difference in the bruise size in the placebo group, which can be due to the short duration of these two studies, specifically with respect to the wound type.

Consistent with the current study, Frost et al. [25], Sowa et al. [21], Miškulin et al. [19], Gilca et al. [32], Alamgir [33], and
Jarić et al. [34] highlighted the anti-bruising effects of Comfrey. However, these studies only addressed the properties of Comfrey or its effects on variables other than bruising and neglected its anti-bruising effects.

It seems that the anti-inflammatory effects of Comfrey play a role in its anti-bruising effects seen in the Comfrey group. Anders et al. [35] showed that cutaneous medications containing Comfrey root (5\% and 10\%) were as effective as or even more effective than diclofenac, in healing ultraviolet-induced erythema. Moreover, these anti-bruising effects can be due to the plant compounds including allantoin, ellagic acid, and rosmarinic acid [21, 25]. Smith et al. [26] and Staiger [36] highlighted the anti-inflammatory and stimulatory effects of Comfrey on granulation, tissue regeneration, and rapid healing.

Change in bruise color took place sooner in the Comfrey group than the control. Results showed that the bruise color change occurred one day after the intervention in the Comfrey group and 2-3 days after the intervention in the control. The difference in the onset of bruise color change between the groups was significant. As a result, the application of Comfrey ointment could facilitate the bruise color change following enoxaparin injection in the Comfrey group.

Bruising at the injection site is the undesirable result of enoxaparin subcutaneous injection, which can cause physical discomfort $[27,37]$. According to the results, Comfrey ointment can be used to reduce these impacts. Consistent with our findings, different studies mentioned the effectiveness of Comfrey ointment in the rapid healing of trauma-induced bruises. However, these studies only provided a descriptive explanation 
of Comfrey properties and did not scientifically investigate the effect of Comfrey on bruising [38].

According to a study in the Medical University of Lublin, Poland, the Comfrey plant root can facilitate the growth and proliferation of skin fibroblasts [26]. This plant has been effective in improving cutaneous inflammation and skin redness caused by overexposure to ultraviolet (UV) rays, which confirms the findings of the current study $[24,39,40]$.

\section{CONCLUSIONS}

The results showed that comfrey ointment accelerated the healing of enoxaparin injection-induced bruise (size and color) in patients with ACS. Therefore, Comfrey is recommended to be used as a safe, non-aggressive, and simple method to facilitate bruise improvement caused by enoxaparin injection.

\section{ACKNOWLEDGEMENTS}

The authors thank the patient for participating in this study and all clinical staff at Farshchian Heart Hospital (Department of Heart and CCU, Hamadan University of Medical Sciences) for their excellent technical assistance. Financial support for this study was provided by Vice-chancellor for Research and Technology, Hamadan University of Medical Sciences (Grant number: 9709275652).

\section{LIMITATIONS}

Due to early discharge, the effect of Comfrey on complete improvement of bruise, naturally lasting about two weeks, could not be investigated in this study. Therefore, we are not completely certain to what extent this medicinal plant can shorten the healing period. The results of this study only showed the effect of Comfrey ointment on bruise caused by abdominal injection of enoxaparin in patients with ACS. Moreover, the control group could enhance the validity of this study.

\section{CONFLICT OF INTEREST}

The authors declare that they have no financial or nonfinancial conflict of interest.

\section{ETHICAL APPROVAL}

All procedures performed in studies involving human participants were in accordance with the ethical standards of the institutional and/or national research committee and with the 1964 Helsinki declaration and its later amendments or comparable ethical standards. The study has been approved by the Ethical Committee of Hamadan University of Medical Sciences (approval number: IR.UMSHA.REC.1397.471).

\section{RESEARCH REGISTRATION NUMBER}

This study was registered in Iranian Registry of Clinical Trials (IRCT) with registration ID: IRCT2015062822956N1.

\section{FUNDING}

This research has been financially supported by vicechancellor for research and technology, Hamadan University of Medical Sciences, Hamadan, Iran (Grant No.9709275652).

\section{AUTHORS' CONTRIBUTIONS}

Dr. Amir Larki-Harchegani and Dr. Azim Azizi accept full responsibility for this performed study and two authors contributed equally.

\section{ORCID}

Zahra Bagheri, https://orcid.org/0000-0002-8664-4477

Azim Azizi, https://orcid.org/0000-0003-1379-0024

Khodayar Oshvandi, https://orcid.org/0000-0002-2224-8870

Younes Mohammadi, https://orcid.org/0000-0001-7521-4909

Amir Larki-Harchegani, https://orcid.org/0000-0001-9014-6772

\section{REFERENCES}

1. Zipes DP, Libby P, Bonow RO, Mann DL, Tomaselli GF. Braunwald's heart disease e-book: a textbook of cardiovascular medicine. 11th ed. Philadelphia: Elsevier; 2018.

2. Galli M, Andreotti F, D’Amario D, Vergallo R, Vescovo GM, Giraldi L, et al. Antithrombotic therapy in the early phase of non-ST-elevation acute coronary syndromes: a systematic review and meta-analysis. Eur Heart J Cardiovasc Pharmacother. 2020;6(1):43-56.

3. Martinez BK, White CM. Pharmacologic considerations in the 
management of acute coronary syndrome in elderly patients. Expert Opin Pharmacother. 2019;20(15):1787-90.

4. Jupalli A, Iqbal AM. Enoxaparin. Treasure Island: StatPearls Publishing; 2019.

5. Zeitouni M, Kerneis M, Nafee T, Collet JP, Silvain J, Montalescot G. Anticoagulation in acute coronary syndrome-state of the art. Prog Cardiovasc Dis. 2018;60(4-5):508-13.

6. Jameson JL, Fauci A, Kasper DL, Hauser SL, Longo DL, Loscalzo J. Harrison's principles of internal medicine. 20th ed. New York: McGraw-Hill Education; 2018.

7. Hess CT. Clinical guide to skin and wound care. 7th ed. Philadelphia: Lippincott Williams and Wilkins; 2012.

8. Zaybak A, Khorshid L. A study on the effect of the duration of subcutaneous heparin injection on bruising and pain. J Clin Nurs. 2008;17(3):378-85.

9. Bindon SL. Professional development strategies to enhance nurses' knowledge and maintain safe practice. AORN J. 2017; 106(2):99-110.

10. Amaniyan S, Varaei S, Vaismoradi M, Haghani H, Sieloff C. Effect of local cold and hot pack on the bruising of enoxaparin sodium injection site: a randomized controlled trial. Contemp Nurse. 2016;52(1):30-41.

11. Poursafar Z, Jafroudi S, Baghaei M, Kazemnezhad Leyli E, Zarrizei $M$. Incidence and extent of bruising after subcutaneous injection of enoxaparin sodium in patients hospitalized at coronary care units. J Holist Nurs Midwifery. 2019;29(2):90-6.

12. Chan $\mathrm{H}$. Effects of injection duration on site-pain intensity and bruising associated with subcutaneous heparin. J Adv Nurs. 2001;35(6):882-92.

13. Chenicek TE. Effects of injection duration on site-pain intensity and bruising associated with subcutaneous administration of Lovenox (enoxaparin sodium) [master's thesis]. [Tallahassee (FL)]: Florida State University; 2004. 70 p.

14. Taylor CR, Lillis C, Lemone P, Lynn P, Lebon M. Study guide for Fundamentals of nursing: the art and science of nursing care. 7th ed. Philadelphia: Lippincott Williams \& Wilkins; 2011.

15. Bartell JC, Roberts KA, Schutte NJ, Sherman KC, Muller D, Hayney MS. Needle temperature effect on pain ratings after injection. Clin J Pain. 2008;24(3):260-4.

16. Candiotti K, Rodriguez Y, Koyyalamudi P, Curia L, Arheart KL, Birnbach DJ. The effect of needle bevel position on pain for subcutaneous lidocaine injection. J Perianesth Nurs. 2009;24(4): 241-3.

17. Chen S, Shang H, Yang J, Li R, Wu H. Effects of different extraction techniques on physicochemical properties and activities of polysaccharides from comfrey (Symphytum officinale L.) root. Ind Crops Prod. 2018;121:18-25.

18. Jedlinszki N, Balazs B, Csanyi E, Csupor D. Penetration of lyco- psamine from a comfrey ointment through human epidermis. Regul Toxicol Pharmacol. 2017;83:1-4.

19. Miškulin I, Lalić Z, Miškulin M, Dumić A, Šebo D, Včev A, editors. Efficacy of ointment containing comfrey and propolis in the treatment of mild acute sports injuries. Proceedings of World Congress Integrative Medicine \& Health 2017; 2017 May 3-5; Berlin, Germany. London (UK): BioMedCentral; c2017.

20. Nossa GDL, Talero PYV, Rozo NEW. Determination of polyphenols and antioxidant activity of polar extracts of comfrey (Symphytum officinale L). Rev Cubana Plant Med. 2016;21(2):12532.

21. Sowa I, Paduch R, Strzemski M, Zielińska S, Rydzik-Strzemska E, Sawicki J, et al. Proliferative and antioxidant activity of Symphytum officinale root extract. Nat Prod Res. 2018;32(5):605-9.

22. Staiger C. Comfrey root: from tradition to modern clinical trials. Wien Med Wochenschr. 2013;163(3-4):58-64.

23. Trifan A, Opitz SEW, Josuran R, Grubelnik A, Esslinger N, Peter $S$, et al. Is comfrey root more than toxic pyrrolizidine alkaloids? Salvianolic acids among antioxidant polyphenols in comfrey (Symphytum officinale L.) roots. Food Chem Toxicol. 2018;112:178-87.

24. European Scientific Cooperative on Phytotherapy. ESCOP monographs. 2nd ed. Exeter: ESCOP; 2003.

25. Frost R, O'Meara S, MacPherson H. The external use of comfrey: a practitioner survey. Complement Ther Clin Pract. 2014; 20(4):347-55.

26. Smith DB, Jacobson BH. Effect of a blend of comfrey root extract (Symphytum officinale L.) and tannic acid creams in the treatment of osteoarthritis of the knee: randomized, placebocontrolled, double-blind, multiclinical trials. J Chiropr Med. 2011;10(3):147-56.

27. Jafroudi S. Study of effect of subcutaneous enoxaparin sodium injection duration on incidence and extent of bruising at injection site in hospitalized patient [master's thesis]. [Rasht]: Shahid Beheshti Nursing and Midwifery College; 2015.

28. Amidi N, Moradkhani S, Sedaghat M, Khiripour N, Larki-Harchegani A, Zadkhosh N, et al. Effect of green tea on inflammation and oxidative stress in cisplatin-induced experimental liver function. J HerbMed Pharmacol. 2016;5(3):99-102.

29. Hemmati AA, Larki-Harchegani A, Shabib S, Jalali A, Rezaei A, Housmand G. Wound healing property of milk in full thickness wound model of rabbit. Int J Surg. 2018;54(Pt A):133-40.

30. Barna M, Kucera A, Hladícova M, Kucera M. [Wound healing effects of a Symphytum herb extract cream (Symphytum x uplandicum NYMAN): results of a randomized, controlled doubleblind study]. Wien Med Wochenschr. 2007;157(21-22):569-74. German.

31. Chaiet SR, Marcus BC. Perioperative Arnica montana for re- 
duction of ecchymosis in rhinoplasty surgery. Ann Plast Surg. 2016;76(5):477-82.

32. Gilca M, Tiplica GS, Salavastru CM. Traditional and ethnobotanical dermatology practices in Romania and other Eastern European countries. Clin Dermatol. 2018;36(3):338-52.

33. Alamgir A. Therapeutic use of medicinal plants and their extracts: volume 2: phytochemistry and bioactive compounds. Vol 74. Cham: Springer; 2018.

34. Jarić S, Kostić O, Mataruga Z, Pavlović D, Pavlović M, Mitrović $\mathrm{M}$, et al. Traditional wound-healing plants used in the Balkan region (Southeast Europe). J Ethnopharmacol. 2018;211:311-28.

35. Andres R, Brenneisen R, Clerc J. Relating antiphlogistic efficacy of dermatics containing extracts of Symphytum officinale to chemical profiles. Planta Med. 1989;55(7):643-4.

36. Staiger C. Comfrey: a clinical overview. Phytother Res. 2012; 26(10):1441-8.

37. Dehghani K, Najari Z, Dehghani H. Effect of subcutaneous Enoxaparin injection duration on bruising size in acute coronary syndrome patients. Iran J Nurs Midwifery Res. 2014;19(6):5648.

38. Duke JA. Handbook of medicinal herbs: herbal reference library. Boca Raton: CRC Press; 2018.

39. Weiss R, Fintelmann V. Herbal medicine. 2nd ed. Stuttgart: Thieme; 2000.

40. Korać RR, Khambholja KM. Potential of herbs in skin protection from ultraviolet radiation. Pharmacogn Rev. 2011;5(10):164-73. 